\title{
ANALISIS TATANIAGA KOPI ROBUSTA DI KECAMATAN SUMOWONO KABUPATEN SEMARANG
}

\section{(Marketing Analyisis of Robusta Coffee in Sumowono District, Semarang Regency)}

\author{
M. K. Utama, W. Roessali, W.D. Prastiwi \\ Program Studi Agribisnis Fakultas Peternakan dan Pertanian Universitas Diponegoro \\ Kampus drh. R. Soejono Koesoemowardojo Tembalang Semarang \\ Email : muhammadkhevin@gmail.com
}

Diterima 02 Maret 2018, disetujui 30 Juli 2018

\begin{abstract}
ABSTRAK
Penelitian ini bertujuan 1) Mengidentifikasi saluran tataniaga dan fungsi-fungsi tataniaga, 2) Menganalisis marjin dan farmer's share pada tataniaga kopi Robusta di Kecamatan Sumowono. Penelitian dilaksanakan pada bulan Maret sampai dengan April 2017. Metode penelitian dan pengumpulan data ini adalah survei, observasi, dan wawancara menggunakan kuesioner. Penelitian dilakukan di Kecamatan Sumowono yang merupakan penghasil kopi terbesar di Kabupaten Semarang. Lokasi ditentukan pada 3 desa sentra kopi robusta yaitu Desa Pledokan, Desa Ngadikerso dan Desa Kebonagung, yang dipilih secara purposive. Responden terdiri dari petani dan pedagang kopi Robusta, ditentukan dengan Multistage Sampling berjumlah 30 responden. Responden pedagang dan agen ditentukan dengan metode snowball berjumlah 15 responden. Hasil penelitian menunjukkan bahwa terdapat empat saluran tataniaga yang terjadi di Kecamatan Sumowono yaitu (I) Petani - Pedagang Pengumpul Besar Pedagang Eksportir, (II) Petani - Pedagang Pengumpul Desa - Pengecer - Konsumen, (III) Petani - Pedagang Pengumpul Desa - Pedagang Pengumpul Besar - Pedagang Eksportir, dan (IV) Petani - Pedagang Pengumpul Desa - Pedagang Pengumpul Besar - Pengecer Konsumen. Masing-masing lembaga tataniaga melakukan fungsi tataniaga yang berbeda-beda. Nilai marjin tataniaga dan farmer's share pada pola saluran tataniaga I masing-masing sebesar Rp. 5.983,00 dan 80,70\%, pola saluran II Rp. 6.912,00 dan 78\%, pola saluran III Rp. 8.918,00 dan $74 \%$ dan saluran IV Rp. 10.000,00dan 71\%. Pola saluran I adalah yang paling efisien.
\end{abstract}

Kata Kunci : farmer's share, fungsi, kopi, saluran, tataniaga.

\section{ABSTRACT}

The research objectives are 1) Identifying marketing systems and marketing functions, 2) Analyzing margins and farmer shares in the Robusta coffee marketing system in Sumowono District. The research was conducted from March to April 2017. The research was conducted from March to April 2017. The research method and data collection were surveys, observations, and interviews using questionnaires. The study was conducted in Sumowono Subdistrict, which is the largest coffee producer in Semarang Regency. The location was determined in 3 Robusta coffee center villages, namely Pledokan Village, Ngadikerso Village and Kebonagung Village, 
which were selected purposively. Respondents consisted of farmers and traders of Robusta coffee, determined by Multistage Sampling totaling 30 respondents. Respondents of traders and agents have determined snowball method as many as 15 respondents. The results showed that there were four marketing systems that occurred in Sumowono Subdistrict, namely (I) Farmers - Large Collectors - Exporter Traders, (II) Farmers - Village Collectors - Retailers - Consumers, (III) Farmers - Village Collectors - Collectors Large - Exporter Traders, and (IV) Farmers Village Collectors - Large Collectors - Retailers - Consumers. Each marketing institution performs a different marketing function. The marketing margin and farmer's share values in the marketing system channel I were each Rp. 5,983.00 and 80.70\%, channel II pattern Rp. 6,912.00 and 78\%, channel III pattern Rp. 8,918.00 and 74\% and channel IV Rp. 10,000.00 and $71 \%$. Channel I pattern was the most efficient.

Keywords: farmer's shares, functions, coffee, channels, marketing.

\section{PENDAHULUAN}

Kopi merupakan komoditas tropis utama yang diperdagangkan di seluruh dunia dengan kontribusi setengah dari total ekspor komoditas ekspor. Popularitas dan daya tarik dunia terhadap kopi dikarenakan rasa yang unik serta didukung oleh faktor sejarah, tradisi, sosial dan kepentingan ekonomi (Ayelign et al., 2013). Minuman kopi dengan bahan ekstrak biji kopi, dikonsumsi sekitar 2,25 milyar gelas setiap hari di seluruh dunia (Ponte, 2002). International Coffee Organization (ICO) (2015) memperkirakan bahwa kebutuhan bubuk kopi dunia sekitar 8,77 juta ton.

Kopi Robusta merupakan jenis tanaman kopi yang dapat tumbuh optimum pada ketinggian 400 - $700 \mathrm{mdpl}$ dengan curah hujan $2.000-3.000 \mathrm{~mm} /$ tahun (Najiyati dan Danarti, 2012). Kopi Robusta sudah dapat berproduksi pada umur tanaman 2,5 - 3 tahun (Suwarto et al., 2014). Kopi ini ditanam pada dataran tinggi sekitar 1350-1850 m dari permukaan laut, sedangkan di Indonesia kopi ini dapat tumbuh pada ketinggian 1000 $1750 \mathrm{~m}$ dari permukaan laut (Najiyati dan Danarti, 2012).

Kecamatan Sumowono memiliki luas areal lahan untuk komoditas kopi sebesar $1.161,17$ ha. Memiliki populasi petani kopi sebanyak 4.617 petani dan produksi kopi sebesar 618 Ton (Badan Pusat Statistik Kabupaten Semarang, 2014). Kecamatan Sumowono merupakan kecamatan yang memiliki kontribusi paling besar dalam produksi kopi di antara kecamatan lain di Kabupaten Semarang yaitu sebesar 43,40\%. Penelitian terkait tataniaga kopi Robusta di Kecamatan Sumowono menjadi penting dilakukan karena Kecamatan ini lebih unggul dalam jumlah produksi Kopi Robusta dihasilkan dibanding kecamatan lain di Kabupaten Semarang, walaupun memiliki jumlah populasi petani kopi lebih kecil dibandingkan dengan Kecamatan Jambu yang hanya menghasilkan Kopi Robusta sebesar 523 Ton pada luas areal lahan 920,59 Ha dan jumlah populasi petani kopi sebanyak 5.422 petani.

Tujuan penelitian adalah 1) Mengidentifikasi saluran tataniaga dan fungsi-fungsi tataniaga yang terjadi pada masing-masing lembaga Tataniaga di Kecamatan Sumowono 2) Menganalisis marjin tataniaga dan farmer's share pada tataniaga kopi Robusta di Kecamatan Sumowono.

\section{METODE PENELITIAN}

\section{Waktu dan Lokasi Penelitian}

Penelitian dilaksanakan pada Bulan Maret sampai Bulan April 2017. Lokasi penelitian ditentukan secara purposive dengan pertimbangan bahwa Kecamatan Sumowono merupakan penghasil kopi terbesar yaitu dengan produksi sebear 618 Ton dan kontribusi sebesar 43,40 \% (Badan Pusat Statistik, 2015). 


\section{Metode Penelitian}

Metode penelitian dan pengumpulan data ini adalah survei, observasi, dan wawancara menggunakan kuesioner. Responden adalah petani Kopi Robusta di Kecamatan Sumowono yang sudah pernah melakukan transaksi dengan lembagalembaga tataniaga yang terdapat di Kecamatan Sumowono. Pedagang yang dijadikan responden adalah pedagang yang terlibat dalam penjualan dan pembelian serta alur distribusi produk Kopi Robusta yang berasal dari Kecamatan Sumowono. Variabel yang diamati yaitu tujuan penjualan, perlakuan terhadap produk, harga jual kopi Robusta dan biaya yang dikeluarkan saat proses tataniaga kopi Robusta berlangsung.

\section{Metode Pengambilan Sampel}

Pengambilan sampel petani sebanyak 30 petani dengan menggunakan metode multistage sampling (bertahap). Pertama, dipilih Kecamatan Sumowono yang merupakan sentra produksi Kopi Robusta di Kabupaten Semarang lalu diambil dari 3 desa yang berpotensi menurut Balai Penyuluh Pertanian Kecamatan Sumowono dalam menghasilkan produksi Kopi Robusta yaitu Desa Pledokan, Desa Ngadikerso dan Desa Kebonagung. Kedua, pada masing-masing desa dipilih 1 RW kemudian secara acak dipilih sebanyak 2 RT, selanjutnya diambil secara acak sederhana (simple random sampling) dari masing-masing RT tersebut sebanyak 5 orang yang terlibat dalam saluran tataniaga kopi Robusta di Kecamatan Sumowono dengan asumsi bahwa seluruh petani di Desa Pledokan, Desa Ngadikerso dan Desa Kebonagung bersifat homogen yang artinya memiliki teknik budidaya, luas lahan dan harga jual yang sama.

Pengambilan responden lembaga tataniaga di Kecamatan Sumuwono ini dilakukan dengan metode bola salju (snowball) yaitu 5 pedagang pengumpul desa, 2 pedagang pengumpul besar dan 8 pedagang pengecer yang saling terkait dalam rantai tataniaga. Selain itu dilakukan pengamatan langsung terhadap kegiatan tataniaga dan penelusuran saluran tataniaga atau lembagalembaga tataniaga dari mulai petani, pedagang pengumpul, sampai dengan pedagang pengecer dan konsumen akhir.

\section{Metode Analisis Data}

Metode analisis yang digunakan yaitu analisis deskriptif. Analisis berdasarkan data primer yang bersumber dari responden petani dan responden pedagang yang dilengkapi oleh data kuantitatif yang berasal dari perhitungan marjin tataniaga dan farmer's share. Pola saluran tataniaga diidentifikasi dengan mengkategorikan setiap saluran tataniaga yang muncul. Berdasarkan pola saluran tataniaga dihitung nilai marjin tataniaga dan farmer's share.

Fungsi-fungsi tataniaga dianalisis secara kualitatif pada setiap lembaga tataniaga yang melalui pengukuran 3 aspek fungsi-fungsi tataniaga yang dilakukan pada setiap lembaga tataniaga yaitu fungsi pertukaran, fungsi fisik dan fungsi fasilitas. Analisis ini dilakukan dengan mendeskripsikan setiap lembagalembaga tataniaga terhadap fungsi-fungsi tataniaga yang dilakukan.

Analisis marjin tataniaga dilakukan untuk mengetahui saluran tataniaga yang paling efisien diantara saluran yang lain. Marjin tataniaga merupakan perbedaan harga di tingkat petani produsen dengan harga di tingkat konsumen akhir atau di tingkat retail (Hanafie, 2010). Perbedaan harga yang diterima produsen inilah yang disebut dengan marjin tataniaga, yang dirumuskan sebagai berikut.

Keterangan :

$$
\mathrm{M}=\mathrm{P}_{\mathrm{r}}-\mathrm{P}_{\mathrm{f}}
$$

$\mathrm{M}:$ Marjin tataniaga

$\mathrm{P}_{\mathrm{r}}$ : Harga di tingkat pengecer (retail price)

$\mathrm{P}_{\mathrm{f}}$ : Harga di tingkat petani (farm gate price).

Data yang terkumpul dianalisis secara kualitatif dan kuantitatif yang kemudian dianalisis dengan uji non parametrik. Untuk mengetahui terdapat perbedaan di setiap saluran tataniaga terhadap nilai marjin 
tataniaga yang dihasilkan secara statistik yaitu analisis ragam satu arah (One Way Anova) yaitu uji Kruskall Wallis. Uji Kruskall Wallis adalah uji yang berguna untuk menentukan apakah $\mathrm{k}$ sampel independen berasal dari populasi-populasi yang berbeda (Siegel, 1985). Uji ini dilakukan untuk menguji hipotesis bahwa di setiap saluran tataniaga memiliki perbedaan nilai marjin tataniaga yang nyata. Perhitungan uji hipotesis yang diambil sebagai berikut :

$\mathrm{H}_{0}: \mu=0$ :Tidak ada perbedaan nilai marjin tataniaga yang diperoleh di setiap saluran tataniaga yang terjadi.

$\mathrm{H}_{1}: \mu \neq 0$ :Terdapat perbedaan nilai marjin tataniaga yang diperoleh di setiap saluran tataniaga yang terjadi.

Kriteria pengambilan keputusan yaitu : $\mathrm{H}_{0}$ ditolak dan $\mathrm{H}_{1}$ diterima jika probabilitas $\operatorname{sig}_{\text {hit }} \leq 0,05$.

$\mathrm{H}_{1}$ ditolak dan $\mathrm{H}_{0}$ diterima jika probabilitas $\operatorname{sig}_{\text {hit }}>0,05$.

Analisis farmer's share bermanfaat untuk mengetahui bagian harga yang diterima oleh petani dari harga di tingkat konsumen yang dinyatakan dalam persentase (Sudiyono, 2002). Farmer share diformulasikan sebagai berikut (Asmarantaka, 2011) :

$$
F s=\frac{P f}{P r} \times 100 \%
$$

Keterangan:

$F_{s}=$ Farmer's share

$\mathrm{Pf}=$ Harga di tingkat produsen/petani $(\mathrm{Rp} / \mathrm{kg})$

$\mathrm{Pr}=$ Harga di tingkat konsumen $(\mathrm{Rp} / \mathrm{kg})$

Kaidah keputusan efisiensi farmer's share (Downey dan Erickson, 1992).

Jika nilai $F_{S} \geq 40 \%=$ efisien

Jika nilai $F_{S} \leq 40 \%=$ tidak efisien

\section{HASIL DAN PEMBAHASAN}

\section{Gambaran Umum Daerah Penelitian}

Kecamatan Sumowono membentang seluas $55,63 \mathrm{Km}^{2}$, yang terdiri atas enam belas desa, 60 dusun, 60 rukun warga dan 219 rukun tetangga, dengan jumlah penduduk sebanyak 31.192 jiwa dengan jumlah penduduk laki-laki sebanyak 15.732 jiwa dan penduduk perempuan sebesar 15.460 (Badan Pusat Statistik Kabupaten Semarang, 2014).

Lokasi penelitian yaitu Desa Pledokan, Desa Ngadikerso dan Desa Kebonagung, desa tersebut merupakan desa berpotensi yang disarankan oleh Balai Penyuluh Pertanian Kecamatan Sumowono. Desa Pledokan memiliki luas $3,69 \mathrm{Km}^{2}$ atau $3,69 \%$ luas wilayah Kecamatan Sumowono, jumlah penduduk sebesar 1.291 jiwa, kepadatan 350 jiwa dan pertumbuhan penduduk sebesar 1,49. Desa Ngadikerso memiliki luas $3,88 \mathrm{Km}^{2}$ atau kontribusi wilayahnya sekitar $6,97 \%$ dari seluruh desa di Kecamatan Sumowono, jumlah penduduk sebesar 2.172 jiwa, kepadatan 560 jiwa dan pertumbuhan penduduk di Desa Ngadikerso yaitu sebesar 0,32. Sedangkan Desa Kebonagung memiliki luas $5,00 \mathrm{Km}^{2}$ atau $8,99 \%$ yang merupakan desa yang memiliki kontribusi paling besar dibandingkan dengan Desa Pledokan dan Desa Ngadikerso, jumlah penduduk sebesar 2557 jiwa, kepadatan 511 jiwa dan pertumbuhan penduduk sebesar 0,35 (Badan Pusat Statistik Kabupaten Semarang, 2015).

\section{Analisis Saluran Tataniaga}

Berikut merupakan proses tahapan saluran tataniaga yang digunakan oleh petani kopi Robusta di Kecamatan Sumowono Kabupaten Semarang (Ilustrasi 1).

Saluran tataniaga untuk Kopi Robusta menggunakan keempat saluran tataniaga tersebut. Saluran tataniaga I tingkat merupakan pola tataniaga yang paling sederhana, sedangkan saluran III tingkat merupakan salurang yang paling kompleks yaitu dengan melewati perantara paling banyak. Panjang pendeknya saluran tataniaga tergantung pada jarak antara produsen dan 
Keterangan :

$\mathrm{PPB}=$ Pedagang Pengumpul Besar

$\mathrm{PPD}=$ Pedagang Pengumpul Desa

$\mathrm{PP}=$ Pedagang Pengecer

Ilustrasi 1. Pola tataniaga Kopi Robusta di Kecamatan Sumowono Kabupaten Semarang

konsumen. Semakin jauh jarak antara produsen dan konsumen, maka makin panjang saluran tataniaga yang terjadi (Hanafiah dan Saefuddin, 2004).

\section{Analisis Fungsi Tataniaga}

Fungsi-fungsi tataniaga dianalisis menggunakan kualitatif dimana dengan mengukur setiap lembaga tataniaga yang terdapat di lapangan, melalui pengukuran 3 aspek fungsi-fungsi tataniaga yang dilakukan pada setiap lembaga tataniaga yaitu fungsi pertukaran, fungsi fisik dan fungsi fasilitas. Hasil penenlitian menunjukkan setiap lembaga tataniaga melakukan fungsi-fungsi tataniaga yang berbeda dengan tujuan untuk memperluas penjualan Kopi Robusta. Fungsi tataniaga merupakan aktivitas penting yang dispesialiasi dan dijalankan pada proses tataniaga (Hutauruk, 2003). Analisis ini dilakukan dengan mendeskripsikan setiap lembaga-lembaga tataniaga terhadap fungsifungsi tataniaga yang dilakukan. Hasil analisis fungsi tataniaga tertera pada Tabel 1 . Hasil Penelitian yang dilakukan oleh Palele et al. (2016) menunjukkan bahwa seluruh fungsi-fungsi tataniaga dilakukan semua oleh pedagang pengumpul tingkat kota, hal ini dikarenakan pedagang pengumpul besar menjual produk dengan volume yang relatif banyak sehingga perlakuan untuk memasarkan produknya semakin banyak.

\section{Marjin Tataniaga Kopi Robusta}

Marjin tataniaga merupakan perbedaan harga di tingkat petani atau produsen dengan harga di tingkat konsumen akhir atau tingkat lembaga tataniaga akhir. Analisis marjin tataniaga dapat dilihat pada Tabel 2.

Berdasarkan Tabel 2 diketahui bahwa semakin banyak pedagang atau perantara yang terlibat maka semakin besar nilai marjin tataniaga Kopi Robusta, sementara jika saluran tataniaga yang dilewati pendek, maka nilai marjin tataniaga pun semakin kecil. Hal ini sesuai dengan pendapat Hanafie (2010) yang menyatakan bahwa marjin tataniaga dilakukan untuk mengetahui saluran tataniaga yang paling efisien diantara saluran yang lain. Marjin tataniaga akan tinggi akibat pendapatan yang diperoleh kecil. Hasil analisis saluran 2 dan 3 memiliki kesamaan yaitu melibatkan dua pedagang perantara 
tetapi memiliki nilai marjin tataniaga yang

Tabel 1. Fungsi-Fungsi Tataniaga yang Dilakukan oleh Lembaga Tataniaga Kopi Robusta di Kecamatan Sumowono $(\mathrm{n}=45)$

\begin{tabular}{|c|c|c|c|c|c|c|c|c|}
\hline \multirow{3}{*}{$\begin{array}{c}\text { Saluran } \\
\text { Tataniaga }\end{array}$} & \multicolumn{8}{|c|}{ Fungsi Tataniaga } \\
\hline & \multicolumn{2}{|c|}{ Pertukaran } & \multicolumn{2}{|c|}{ Fisik } & \multicolumn{4}{|c|}{ Fasilitas } \\
\hline & Jual & Beli & Simpan & Angkut & Sortasi & Risiko & Pembiayaan & Informasi \\
\hline \multicolumn{9}{|l|}{ Saluran I } \\
\hline Petani & $\sqrt{ }$ & - & $\sqrt{ }$ & - & - & - & - & $\sqrt{ }$ \\
\hline PPB & $\sqrt{ }$ & $\sqrt{ }$ & $\sqrt{ }$ & $\sqrt{ }$ & $\sqrt{ }$ & $\sqrt{ }$ & $\sqrt{ }$ & $\sqrt{ }$ \\
\hline \multicolumn{9}{|l|}{ Saluran II } \\
\hline Petani & $\sqrt{ }$ & - & $\sqrt{ }$ & - & - & - & - & $\sqrt{ }$ \\
\hline PPD & $\sqrt{ }$ & $\sqrt{ }$ & - & $\sqrt{ }$ & - & - & $\sqrt{ }$ & $\sqrt{ }$ \\
\hline Pengecer & $\sqrt{ }$ & $\sqrt{ }$ & - & $\sqrt{ }$ & - & - & $\sqrt{ }$ & $\sqrt{ }$ \\
\hline \multicolumn{9}{|l|}{ Saluran III } \\
\hline Petani & $\sqrt{ }$ & - & $\sqrt{ }$ & - & - & - & - & $\sqrt{ }$ \\
\hline PPD & $\sqrt{ }$ & $\sqrt{ }$ & - & $\sqrt{ }$ & - & - & $\sqrt{ }$ & $\sqrt{ }$ \\
\hline PPB & $\sqrt{ }$ & $\sqrt{ }$ & $\sqrt{ }$ & $\sqrt{ }$ & $\sqrt{ }$ & $\sqrt{ }$ & $\sqrt{ }$ & $\sqrt{ }$ \\
\hline \multicolumn{9}{|l|}{ Saluran IV } \\
\hline Petani & $\sqrt{ }$ & - & $\sqrt{ }$ & - & - & - & - & $\sqrt{ }$ \\
\hline PPD & $\sqrt{ }$ & $\sqrt{ }$ & - & $\sqrt{ }$ & - & - & $\sqrt{ }$ & $\sqrt{ }$ \\
\hline PPB & $\sqrt{ }$ & $\sqrt{ }$ & $\sqrt{ }$ & $\sqrt{ }$ & $\sqrt{ }$ & $\sqrt{ }$ & $\sqrt{ }$ & $\sqrt{ }$ \\
\hline Pengecer & $\sqrt{ }$ & $\sqrt{ }$ & - & $\sqrt{ }$ & - & - & $\sqrt{ }$ & $\sqrt{ }$ \\
\hline
\end{tabular}

Sumber : Data Primer Penelitian Terolah, 2017

Keterangan : $\sqrt{ }=$ Melakukan fungsi tataniaga

- = Tidak melakukan fungsi tataniaga

Tabel 2. Rata-rata Marjin Tataniaga pada Setiap Saluran Tataniaga Kopi Robusta

\begin{tabular}{clc}
\hline No & \multicolumn{1}{c}{ Saluran Tataniaga } & Marjin Tataniaga \\
\hline & & $----\mathrm{Rp} / \mathrm{kg}-----$ \\
1 & Satu Tingkat (Satu Perantara) P - PPB - PEK & $5.983,00$ \\
2 & Dua Tingkat (Dua Perantara) P - PPD - PP - K & $6.913,00$ \\
3 & Dua Tingkat (Dua Perantara) P - PPD - PPB - PEK & $8.918,00$ \\
4 & Tiga Tingkat (Tiga Perantara) P - PPD - PPB - PP - K & $11.000,00$ \\
\hline
\end{tabular}

$\begin{aligned} \text { Keterangan : } \mathrm{P} & =\text { Petani } \\ \mathrm{PPD} & =\text { Pedagang Pengumpul Desa } \\ \mathrm{PPB} & =\text { Pedagang Pengumpul Besar } \\ \mathrm{PP} & =\text { Pedagang Pengecer } \\ \mathrm{PEK} & =\text { Pedagang Eksportir } \\ \mathrm{K} & =\text { Konsumen }\end{aligned}$


Tabel 3. Rata-rata Nilai Farmer's Share Petani Kopi Robusta di Kecamatan Sumowono

\begin{tabular}{llc}
\hline No & \multicolumn{1}{c}{ Saluran Tataniaga } & Farmer's Share \\
\hline & & $---\%^{-----}$ \\
1 & Satu Tingkat (Satu Perantara) P - PPB - PEK & 80,70 \\
2 & Dua Tingkat (Dua Perantara) P - PPD - PP - K & 78,00 \\
3 & Dua Tingkat (Dua Perantara) P - PPD - PPB - PEK & 74,00 \\
4 & Tiga Tingkat (Tiga Perantara) P - PPD - PPB - PP - K & 71,00 \\
\hline
\end{tabular}

Sumber: Data Primer Terolah, 2017.

berbeda. Hasil penelitian Caesara et al. (2017) menunjukkan bahwa saluran tataniaga dengan melibatkan jumlah perantara yang sama menghasilkan nilai marjin yang berbeda, hal ini dikarenakan adanya perbedaan harga jual pada tingkat perantara akhir. Berbeda dengan hasil penelitian Sujiwo et al. (2007) menunjukkan bahwa nilai marjin tataniaga yang diperoleh sama ketika harga jual di tingkat produsen dan pedagang akhir selalu sama.

\section{Analisis Farmer's Share}

Farmer's share merupakan nilai untuk mengukur bagian yang diterima oleh produsen atau petani dengan cara membandingkan harga jual di tingkat produsen atau petani dengan harga jual di tingkat pedagang akhir. Rata - rata nilai farmer's share yang didapatkan oleh para petani Kopi Robusta di Kecamatan Sumowono dapat dilihat pada Tabel 3.

Berdasarkan Tabel 3 rata-rata nilai farmer's share pada tiap pola tataniaga berbeda-beda. Masing-masing nilai farmer's share Kopi Robusta pada pola tataniaga 1,2,3 dan 4 yaitu $80.70 \%, 78.00 \%, 74.00 \%$ dan $71.00 \%$. Berdasarkan hasil tersebut dapat diketahui bahwa semakin panjang suatu pola tataniaga yang dilalui maka semakin kecil nilai farmer's share atau nilai yang diterima oleh produsen atau petani, sehingga produsen atau petani memperoleh bagian yang semakin kecil jika menggunakan pola tataniaga yang melibatkan banyak pedagang perantara, dapat dibandingkan juga bahwa semakin tinggi nilai farmer's share yang diperoleh produsen atau petani maka semakin rendah marjin tataniaga yang didapat. Kesimpulan dari analisis farmer's share ini diketahui bahwa seluruh pola tataniaga Kopi Robusta di Kecamatan Sumowono sudah efisien, karena nilai farmer's share yang diperoleh pola tataniaga $1,2,3$ dan 4 mencapai lebih dari $50 \%$. Semakin banyak perantara yang terlibat dalam suatu saluran maka pendapatan yang terima oleh petani semakin kecil (Hanafie, 2010). Sesuai dengan hasil penelitian Desiana et al. (2017) menunjukkan bahwa pola saluran tataniaga I tingkat mendapatkan nilai farmer's share sebesar $98,14 \%$ dan saluran tataniaga II tingkat sebesar 94,35\%, hal ini membuktikan bahwa semakin banyak perantara yang terlibat semakin kecil nilai farmer's share yang diperoleh petani.

\section{SIMPULAN DAN SARAN}

Berdasarkan hasil penelitian analisis saluran tataniaga kopi robusta di Kecamatan Sumowono terdapat empat macam saluran yaitu saluran I yaitu petani - pedagang pengumpul besar - pedagang eksportir, saluran II yaitu petani - pedagang pengumpul desa - pedagang pengecer - konsumen, saluran III yaitu petani - pedagang pengumpul besar - pedagang pengecer konsumen dan saluran IV yaitu petani pedagang pengumpul desa - pedagang pengumpul besar - pedagang pengecer konsumen. Fungsi tataniaga kopi robusta di Kecamatan berbeda-beda, hanya pedagang pengumpul besar melaksanakan semua fungsi-fungsi tataniaga (pertukaran, fisik dan fasilitas). 
Marjin tataniaga kopi robusta terbesar diperoleh pada saluran tataniaga IV yaitu sebesar Rp 11.000. Farmer's share kopi robusta di Kecamatan Sumowono sudah efisien, saluran yang paling efisien pada saluran tataniaga I.

\section{DAFTAR PUSTAKA}

Asmarantaka, R. W. 2012. Pemasaran Agribisnis. Departemen Agribisnis Fakultas Ekonomi dan Manajemen IPB. Bogor.

Ayelign, A. dan K. Sabally. 2013. Determination of chlorogenic acids (CGA) in coffee beans using HPLC. American Journal of Research Communication. 1(2): 78-91.

Badan Pusat Statistik. 2015. Jawa Tengah dalam Angka. BPS, Semarang.

Caesara, V., B. Akhmad dan M. Usman. 2017. Analisis pendapatan dan efisiensi pemasaran biji kopi arabika di Kabupaten Bener Meriah Aceh. J. Ilmiah Mahasiswa AGROINFO. 4(2) : $162-173$.

Desiana, C., R. Dini, dan C. Pardani. 2017. Analisis saluran pemasaran biji kopi robusta di Desa Kalijaya Kecamatan Banjarsari Kabupaten Ciamis. J. Ilmiah Mahasiswa Pertanian Unsyiah. 2(1) : 250-261.
Downey, W. D. dan S. P. Erickson. 1992. Manajemen Agribisnis. Erlangga, Jakarta.

Hanafiah, A. M. dan Saefuddin. 2006. Tataniaga Hasil Pertanian. Universitas Indonesia (UI) Press. Jakarta.

Hanafie, R. 2010. Pengantar Ekonomi Pertanian. Penerbit ANDI. Yogyakarta.

Najiyati, S. dan Danarti. 2012. Kopi, Budidaya dan Penanganan Lepas Panen. PT. Penebar Swadaya. Jakarta.

Palele, J., R. Darma, dan Saadah. 2016. Analisis Saluran Pemasaran Kopi Biji Arabika (Studi Kasus di Keluarahan Benteng Ambeso Kecataman Gandang Batu Silanan Kabupaten Tana Toraja). Universitas Hassanudin. Sulawesi Selatan.

Ponte, S. 2002. The 'latte revolution'? regulation, markets and consumption in the global coffee chain. world development. 30 (7): 1099-1122.

Siegel, S. 1985. Statistika Nonparametrik Terjemahan M. Sudrajat S. W. Armico, Bandung.

Sudiyono, A. 2004. Pemasaran Pertanian, Cetakan IV, UMM Press, Malang.

Suwarto, S. Hermawati, dan Y. Octaviany. 2014. Top 15 Tanaman Perkebunan. Penerbit Penebar Swadaya, Jakarta. 